Gazi University
Journal of Science
http://dergipark.gov.tr/gujs

\title{
Gallium Oxide: A Rising Star in the Semiconductor Realm
}

\author{
Matteo Bosi ${ }^{1, *}$ (D) , Roberto Fornari ${ }^{1,2}$ (D) \\ ${ }^{1}$ IMEM-CNR, Area delle Scienze 37A, 43124 Parma, Italy \\ ${ }^{2}$ Department of Mathematical, Physical, and Computer Sciences, University of Parma, Area delle Scienze 7/A, 43124 Parma, Italy
}

A "new" semiconductor can gather the interest of the scientific community only when it adds unprecedented properties to the ones already established, with silicon universally considered as the most widespread and the primary benchmark. In the last decades, this happened for example with III-V and III-N semiconducting compounds, capable of emitting and absorbing light and to process signals of much higher frequencies than silicon. More recently, this newly happened with silicon carbide, which can work at higher voltages and power than previously available semiconductors, and with layered transition metal dichalcogenides, for their unusual properties and potential applications in nanoelectronics.

The potentialities offered by high performance semiconductor devices are the main boost for the development of our civilization. In particular, energy production, distribution and conversion are one of the most important challenges of nowadays society, with a particular emphasis on sustainability and energy efficiency. It is widely accepted that silicon, when it comes to handling very high power, has many drawbacks due to its physical characteristics. Despite its limit, silicon is still widely adopted in power devices fabrication, because of the lack of alternatives. This however results in devices with limited efficiency, large size and important cooling requirements. Gallium nitride ( $\mathrm{GaN}$ ) and silicon carbide (SiC) have a higher bandgap with respect to $\mathrm{Si}$ (respectively $3.4 \mathrm{eV}$ and $3.2 \mathrm{eV}$, compared to $1.1 \mathrm{eV}$ ) and permitted the design of innovative power devices with much lower intrinsic losses, less cooling demand and reduced size. These devices were readily adopted in electric motor vehicles, DC-AC conversion for renewable energy and power transmission controls for electric motors, railways and ships.

Talking about high-efficiency power electronics, gallium oxide $\left(\mathrm{Ga}_{2} \mathrm{O}_{3}\right)$ appeared as a new candidate on the stage a few years ago. It cannot be defined as new material indeed, as the first paper on $\mathrm{Ga}_{2} \mathrm{O}_{3}$ dates back 1952, when several $\mathrm{Ga}_{2} \mathrm{O}_{3}$ polymorphs were observed and studied [1]. In 1965 its bandgap was assessed to about $4.7 \mathrm{eV}$ [2], and in the 90's preliminary experiments for the growth of bulk crystals and epitaxial layers of $\mathrm{Ga}_{2} \mathrm{O}_{3}$ were successfully attempted. But it was only in the last 10 years that the crystallographic quality and physical properties of $\mathrm{Ga}_{2} \mathrm{O}_{3}$ enabled the realization of novel power devices with performances that could overtake those of $\mathrm{SiC}$ and $\mathrm{GaN}$. In an energy-dependent society, where efficiency and energy saving are directly linked to sustainability, "green economy" and to climate change mitigation, this was immediately recognized to be of paramount importance. Furthermore, the possibility of alloying $\mathrm{Ga}_{2} \mathrm{O}_{3}$ with $\mathrm{In}$ and $\mathrm{Al}$ allows for tailoring of the bandgap, i.e. absorption of light from visible to deep ultraviolet, which makes the fabrication of innovative light detectors possible, also for solar blind usage. Therefore, a lot of efforts were immediately directed towards a deeper understanding of $\mathrm{Ga}_{2} \mathrm{O}_{3}$ characteristics and to the development of higher performance devices. This is proven by the increasing 
numbers of papers indexed by the most common scientific search engines, and also by the citation of these papers: for example, considering just 2018, Scopus reports 462 papers with ("gallium oxide" $\mathrm{OR} \mathrm{Ga}_{2} \mathrm{O}_{3}$ ) keyword in title or abstract. The most cited review paper [3] has, at the moment of writing this letter, 247 citations. Moreover, there are right now 84 papers published in 2018 with 10 or more (up to 100) citations and 90 more between 5 and 9 citations: this should be a good benchmark in understanding the acceptance of $\mathrm{Ga}_{2} \mathrm{O}_{3}$ research in the scientific community.

At this point the reader might be interested in knowing more about $\mathrm{Ga}_{2} \mathrm{O}_{3}$ and its peculiarities, but going into details would mean to go beyond the scope of a short letter to the editor, especially considering excellent review papers [3-7], and even a recent book devoted to this semiconducting oxide [8]. In this letter we would rather like to stress the importance of $\mathrm{Ga}_{2} \mathrm{O}_{3}$ in the framework of the international scientific community, to stimulate ideas and networking, and to (try to) promote new lines of research.

Studies on $\mathrm{Ga}_{2} \mathrm{O}_{3}$ growth, physics, defect characterization, dielectric integration, have increasingly carried out in the past few years but many aspects are still unknown. Higashiwaki and Jessen in [5] pointed out that "practical power switching and RF device applications require more advanced device architectures and thus demand further improvements in all aspects of melt/epitaxial growth, doping, and device processing and deeper understanding of fundamental material properties to be included in new modelling capabilities that are accurate under high electric field operating conditions. $R \& D$ in the next decade is certainly crucial for the road to industrialization of $\mathrm{Ga}_{2} \mathrm{O}_{3}$ electronic devices."

A lot of work is still needed in order to understand the physical properties of $\mathrm{Ga}_{2} \mathrm{O}_{3}$ and to improve its technology: the most critical aspects are related to epitaxial growth, ohmic contacts, thermally stable Schottky contacts, enhancement-mode (i.e. normally-off) transistor operation, reduction of dynamic onresistance, process integration, and thermal management through passive and active cooling [9].

While the development of epitaxial growth techniques or the realization of bulk ingots to be used as substrates usually requires massive investment in equipment, there are other aspects such as material characterization, development of electric contacts or device simulation that could be faced on a "curiosity driven" basis with relatively small funding. To start working on $\mathrm{Ga}_{2} \mathrm{O}_{3}$ in this historical period means joining an ever-growing community, and (good) papers on this subject have high probability of attracting attention and citations. Specific workshops have been organized, and topical sessions on $\mathrm{Ga}_{2} \mathrm{O}_{3}$ are often included in traditional semiconductors and materials conferences.

It will surely take quite a long time for $\mathrm{Ga}_{2} \mathrm{O}_{3}$ to become commercially mature and widely applied. Let's remember, for example, that it took more than 30 years for $\mathrm{SiC}$ to go from initial concept to device commercialization. Nevertheless, enthusiasm of researchers and financial support to $\mathrm{Ga}_{2} \mathrm{O}_{3}$ research are the keys to reach this ultimate goal within a reasonable time. Japan, Germany and USA are the nations that currently invest more on $\mathrm{Ga}_{2} \mathrm{O}_{3}$ development, but hopefully many more contributors will come up in other countries. As in many previous cases of material development, the international effort has to last long enough to make $\mathrm{Ga}_{2} \mathrm{O}_{3}$ technology mature and affordable. With this letter, the authors aim at promoting research on $\mathrm{Ga}_{2} \mathrm{O}_{3}$, stimulating more researchers to enter the field and speed up its progress.

\section{REFERENCES}

[1] Roy R., Hill V. G. and Osborn E. F., "Polymorphism of Ga2O3 and the System $\mathrm{Ga}_{2} \mathrm{O}_{3}-\mathrm{H} 2 \mathrm{O}$ ", J. Am. Chem. Soc., 74: 719 (1952).

[2] Tippins H. H., "Optical Absorption and Photoconductivity in the Band Edge of $\beta-\mathrm{Ga}_{2} \mathrm{O}_{3}$ ", Phys. Rev., 140: A316-9 (1965). 
[3] Pearton S. J., Yang J., Cary P. H., Ren F., Kim J., Tadjer M. J. and Mastro M. A., "A review of $\mathrm{Ga}_{2} \mathrm{O}_{3}$ materials, processing, and devices", Appl. Phys. Rev., 5: 011301 (2018).

[4] Pearton S. J., Ren F., Tadjer M. and Kim J., "Perspective: $\mathrm{Ga}_{2} \mathrm{O}_{3}$ for ultra-high power rectifiers and MOSFETS", J. Appl. Phys. 124: 220901 (2018).

[5] Higashiwaki M. and Jessen G. H., "Guest Editorial: The dawn of gallium oxide microelectronics", Appl.Phys. Lett. 112: 060401 (2018).

[6] Teherani F. H., Khodaparast G. A., Xu Y. V., Wu J., Dravid V. P., Pavlidis D., Razeghi M., McClintock R., Rogers D. J., Park J-H. and Magill B. A., "A review of the growth, doping, and applications of Beta- $\mathrm{Ga}_{2} \mathrm{O}_{3}$ thin films", Oxide-based Mater. Devices IX 25 (2018).

[7] Wellmann P. J., "Power Electronic Semiconductor Materials for Automotive and Energy Saving Applications - SiC, GaN, $\mathrm{Ga}_{2} \mathrm{O}_{3}$, and Diamond", Zeitschrift fur Anorg. und Allg. Chemie, 643: 13121322 (2017).

[8] Pearton S. J., Ren F. and Mastro M., "Gallium Oxide, Technology, Devices, Applications", Paperback ISBN: 9780128145210, eBook ISBN: 9780128145227, Elsevier Press, (2018).

[9] Mastro M. A., Kuramata A., Calkins J., Kim J., Ren F. and Pearton S. J., "Perspective - Opportunities and Future Directions for $\mathrm{Ga}_{2} \mathrm{O}_{3}$ ", ECS J. Solid State Sci. Technol., 6 (5): 356-359 (2017). 


\section{Dr. Matteo Bosi}

IMEM-CNR

Area delle Scienze 37A, 43124 Parma, Italy matteo.bosi@imem.cnr.it

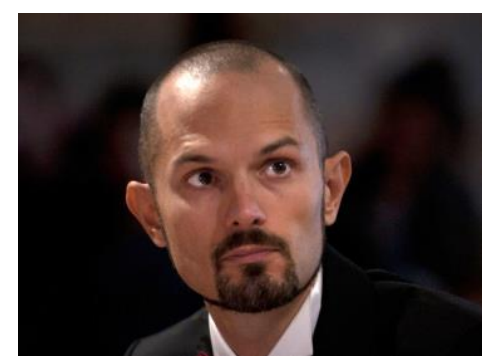

Dr. Matteo Bosi obtained his degree in physics in 2000 and his $\mathrm{PhD}$ in 2003 at the Parma University (Italy). He worked as a post-doc / grant in IMEM from 2003 to 2009, and since 2009 he obtained a permanent researcher position.

His scientific activity has always been focused on epitaxial deposition by means of Metal Organic Vapor Phase Epitaxy (MOVPE) of semiconductors materials for photovoltaic, sensor and optoelectronic devices.

During his career he studied the epitaxy / synthesis of arsenides and phosphides (GaAs, InGaP, AlGaAs), germanium, $\mathrm{SiC}$, diluted nitrides ( $\mathrm{GaAsN})$ and III-nitrides ( $\mathrm{GaN}, \mathrm{InGaN})$, nanowires $(\mathrm{Ge}, \mathrm{SiC})$ and transition metal dichalcogenides $\left(\mathrm{MoS}_{2}\right)$, oxides $\left(\mathrm{TiO} 2, \mathrm{Ga}_{2} \mathrm{O}_{3}\right)$.

During his career Dr. Matteo Bosi attended about 20 international conferences with several invited talks and he is author or co-author of about 100 papers on international peer-reviewed journals.

\section{Prof. Dr. Roberto Fornari}

UNIVERSITY OF PARMA via Università, 12 - I 43121 Parma, Italy roberto.fornari1@ fis.unipr.it

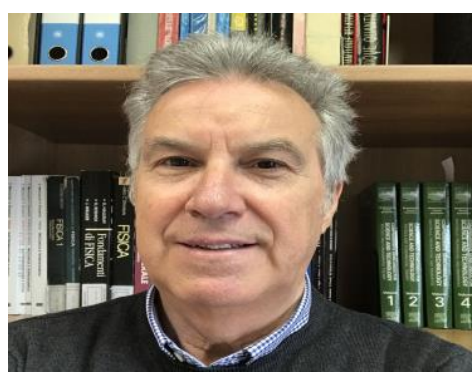

Roberto Fornari studied Physics at the University of Parma where he graduated with honors (con lode) in 1980. 1981 - 2003 he was research scientist at the Institute of Materials for Electronics and Magnetism (IMEM-CNR). 2003 - 2013 he was professor at the Physics Dept. of the Humboldt University Berlin and director of the Leibniz Institute for Crystal Growth (IKZ) in Berlin, joint appointment.

From October 2013 he is full professor of Condensed Matter Physics at the University of Parma (Italy), where he also serves as Vice-Rector for Research.

Fornari's research activity has mainly been focused on semiconductor science and technology, and its scientific production includes some 170 papers in international journals and over 60 papers in conference proceedings, 11 patents and several chapters in specialized books. He has edited books and conference proceedings, and is currently Associate Editor of J. Crystal Growth, Cryst. Res. Technol., J. Optoelectronics and Advanced. Materials. He served in numerous scientific bodies and commissions and chaired twelve international conferences and four schools. 